\title{
A nationwide analysis of the excess death attributable to diabetes in Brazil
}

\author{
Paula A Bracco ${ }^{1}$, Edward \\ W Gregg ${ }^{2}$, Deborah \\ B Rolka ${ }^{3}$, Maria Inês \\ Schmidt $^{1}$, Sandhi M \\ Barreto $^{4}$, Paulo A Lotufo ${ }^{5}$, \\ Isabela Bensenor ${ }^{5}$, Dora \\ Chor $^{6}$, Bruce B Duncan ${ }^{1}$
${ }^{1}$ Postgraduate Program in Epidemiology, School of Medicine and Hospital de Clínicas de Porto Alegre, Universidade Federal do Rio Grande do Sul, Porto Alegre, Rio Grande do Sul, Brazil and Cardiovascular Disease Epidemiology, School of Public Health, Imperial College London, UK
${ }^{3}$ National Center for Chronic Disease Prevention and Health Promotion, Division of Diabetes Translation, Center of Disease Control, Atlanta, Georgia, USA Medicine, School of Medicine, Universidade Federal de Minas Gerais, Belo Horizonte, MG, Brazil
${ }^{5}$ Department of Internal Medicine, School of Medicine, University of Sao Paulo, São Paulo, SP, Brazil Health Quantitative Methods, National School of Public Health, Oswaldo Cruz Foundation, Rio de Janeiro, RJ, Brazil \\ ${ }^{2}$ Department of Diabetes \\ ${ }^{4}$ Department of Preventive and Social \\ ${ }^{6}$ Department of Epidemiology and
}

\section{Correspondence to:}

Paula A Bracco

R. Ramiro Barcelos

2600/514

Porto Alegre

RS 90035-003

Brazil

paula.abracco@gmail.com
Background Data on mortality burden and excess deaths attributable to diabetes are sparse and frequently unreliable, particularly in low and middle-income countries. Estimates in Brazil to date have relied on death certificate data, which do not consider the multicausal nature of deaths. Our aim was to combine cohort data with national prevalence and mortality statistics to estimate the absolute number of deaths that could have been prevented if the mortality rates of people with diabetes were the same as for those without. In addition, we aimed to estimate the increase in burden when considering undiagnosed diabetes.

Methods We estimated self-reported diabetes prevalence from the National Health Survey (PNS) and overall mortality from the national mortality information system (SIM). We estimated the diabetes mortality rate ratio (rates of those with vs without diabetes) from the Brazilian Longitudinal Study of Adult Health (ELSA-Brasil), an ongoing cohort study. Joining estimates from these three sources, we calculated for the population the absolute number and the fraction of deaths attributable to diabetes. We repeated our analyses considering both self-reported and unknown diabetes, the latter estimated based on single point-in-time glycemic determinations in ELSA-Brasil. Finally, we compared results with diabetes-related mortality information from death certificates.

Results In 2013, 65581 deaths, 9.1\% of all deaths between the ages of 35-80, were attributable to known diabetes. If cases of unknown diabetes were considered, this figure would rise to $14.3 \%$. In contrast, based on death certificates only, $5.3 \%$ of all death had diabetes as the underlying cause and $10.4 \%$ as any mentioned cause.

Conclusions In this first report of diabetes mortality burden in Brazil using cohort data to estimate diabetes mortality rate ratios and the prevalence of unknown diabetes, we showed marked underestimation of the current burden, especially when unknown cases of diabetes are also considered.

Diabetes mellitus, given its growing prevalence and its diverse ensuing morbidity, is one of the world's major chronic threats to public health. With a global prevalence in 2017 estimated as 8.8\%, diabetes currently affects approximately 425 million individuals between 20 and 79 years worldwide [1]. The prevalence of diabetes in Brazil, as in most countries of the world, has increased dramatically. Self-reported medical diagnosis of diabetes in Brazilian state capital cities increased from 5.5\% in 2006 to $8.9 \%$ in 2016 [2]. Additionally, between 2010 and 2015, estimated diabetes prevalence increased approximately 450000 cases per year [3].

Although prevalence data are readily available or can be estimated for most countries in the world, data on the mortality burden and excess deaths attributable to diabetes are sparse and frequently unreliable, particularly in low and middle-income countries where an estimated $75 \%$ of diabetes cases live [4]. Mortality in- 
formation systems in these countries are frequently incomplete and inaccurate. Even when complete, the subjective assignment of diabetes as a cause of death on death certificates likely leads to underestimates of the diabetes mortality burden [5]. For these countries, the mortality burden could be worse than in high-income countries, as fewer resources are available to treat the disease and its complications. A recent prospective study in Mexico highlighted this potential, concluding that the rate of death from any cause among those with diabetes was close to four times that of those without, and that the excess risk associated with self-reported diabetes accounted for 30\% of all deaths [6].

Given the limitations of death certificate data and that estimates of the diabetes mortality burden in Brazil to date have relied on death certificates, they are of questionable validity. Epidemiologic mortality data from prospective cohorts following individuals with and without diabetes can be used as an alternative approach to better estimate a disease mortality burden, allowing the calculation of the number of excess deaths attributable to the disease, ie, the deaths due to the increased mortality rate among those with the disease and that could be potentially preventable if the mortality rate among those with the disease were the same as those without [7].

Thus, to evaluate the impact of diabetes on excess mortality in Brazil, we combined cohort data with national prevalence and death statistics to calculate the absolute number of deaths attributable to diabetes, potentially preventable if the mortality rate between those with and without diabetes were the same. Specifically, our aim was to calculate the proportion of total deaths that were due to diabetes for the year 2013 by employing a nationwide analysis combining longitudinal data from a large Brazilian multicenter study with national mortality statistics and prevalence estimates of known and unknown diabetes.

\section{METHODS}

This study models data from three sources - a prospective Brazilian cohort, a nationally representative cross-sectional survey and official compiled data on mortality statistics derived from analyses of nationwide censuses.

\section{Data sources}

Our estimates of diabetes prevalence for the Brazilian population are based on the 2013 National Health Survey (Pesquisa Nacional de Saúde, or PNS). Briefly, the PNS, as described in greater detail elsewhere $[8,9]$, is a nationwide, household-based survey with multistage, probability sampling designed to produce reliable national estimates. In each household, one individual (aged 18 years or more) was selected, with equal probability among the adult residents, to answer personal questions about morbidity and lifestyle. For this analysis, we selected only individuals between 35 and 80 years with information on diabetes status, resulting in a sample of 64308 participants. Survey weights were applied to account for the complex sampling design and to make estimates representative of the national non-institutionalized population of Brazil. Self-reported diabetes prevalence was assessed by the question "Has a doctor ever told you that you have diabetes?". Then, to estimate the absolute number of people with diabetes for each gender and in each age group between 35 and 80 years, we multiplied the respective prevalence by the population projection for the year 2013 of the Brazilian Institute of Geography and Statistics [10].

Mortality rates for people with and without diabetes are not available from representative national sources. Thus, to estimate these rates, we first obtained the mortality rate ratio between individuals with and without diabetes from the Brazilian Longitudinal Study of Adult Health (ELSA-Brasil). ELSA-Brasil is a multicenter cohort study funded by the Brazilian government and designed primarily to investigate the causes and consequences of diabetes and cardiovascular diseases. The cohort comprised of 15105 civil servants, aged 35 to 74 years at baseline (2008-2010), enrolled at universities or research institutions in six cities of three different regions of Brazil $[11,12]$. ELSA-Brasil was approved by institutional review boards at each of its centers; all study subjects gave written informed consent prior to their participation.

Known (self-reported) diabetes was accessed similarly at baseline in ELSA with the question "Has a doctor ever told you that you have diabetes?" ELSA-Brasil participants were followed with an annual telephone interview until July 2018 to assess mortality. In addition, blood samples were collected at baseline to perform laboratory tests. We excluded 16 participants with missing values for diabetes and 239 with missing values for any covariate used in modeling, producing a final data set of 14850 participants and a total of 480 deaths. We used 2013 age and sex-specific Brazilian overall population mortality rates from the National Institute of Geography and Statistics for ages 35 to 80. 


\section{Statistical analysis}

We estimated diabetes prevalence from PNS by sex and age between 35-80 years by logistic regression, including a quadratic term for age. We used SAS SUDAAN to account for the survey sample design and to produce the weighted average marginal estimates. We estimated the mortality rate ratio for diabetes for each sex and age (35-74 years) from the ELSA-Brazil cohort with Cox regression, adjusting for body mass index (BMI), waist circumference, race/color, schooling, income and smoking status, and including interactions terms for age, diabetes and sex. The mortality rate ratio was then extrapolated for ages 75 to 80. We tested the goodness-of-fit of our models in comparison with the null hypothesis through the Likelihood test. In addition, we analyzed the proportional hazard assumption for each variable on our Cox regression model based on weighted Schoenfeld residuals.

We applied the mortality rate ratio to the overall male and female Brazilian mortality rates to obtain the age and sex-specific mortality rates among individuals with and without diabetes. We then used these mortality rates together with the number of people with diabetes in each age and gender strata to estimate the excess deaths due to diabetes in that strata. In addition, we calculated the population-attributable fraction (PAF) as the proportion of total deaths attributable to diabetes for the year 2013, following the method and detailed formulas of Jacobs et al., which were designed for use in situations in which nationwide mortality rates for individuals with and without diabetes are not available [13,14].

To investigate the influence of unknown (undiagnosed) diabetes on our results, we recalculated the diabetes mortality rate ratio and the mortality rates considering as diabetes cases in the ELSA-Brasil sample not only those who self-reported diabetes, but who also met, at a single point in time, at least one of the laboratory criteria for diagnosis (fasting glucose $\geq 126 \mathrm{mg} / \mathrm{dL}(7.0 \mathrm{mmol} / \mathrm{L}$ ) or 2-hour glucose $\geq 200$ $\mathrm{mg} / \mathrm{dL}(11.1 \mathrm{mmol} / \mathrm{L})$ or glycated hemoglobin $(\mathrm{HbAlc}) \geq 6.5 \%(48 \mathrm{mmol} / \mathrm{mol})$. In addition, we also increased our estimates of diabetes prevalence for the Brazilian population based on the proportion of undiagnosed diabetes by age group observed in ELSA-Brasil. We compared the proportion of undiagnosed diabetes among men and women in each age group using Fisher Exact Test. We then recalculated excess deaths and the PAF.

We also compared our results with estimates generated by calculating the proportion of deaths due to diabetes from death certificate information available on the Brazilian Mortality Information System: first, when diabetes was reported as the main cause and second, permitting any mention of diabetes on the death certificate, as opposed to standard underlying cause coding approaches.

All analysis and graphs were performed in SAS 9.4 or SAS-SUDAAN 9.3 (SAS Institute, Cary NC, USA). We considered significant $P$-values $<0.05$.

\section{RESULTS}

The prevalence of known diabetes in the National Health Survey was higher in women than in men (Figure 1), with the highest prevalence occurring around age 75 (approximately 23\% for women and 18\% for men). The proportion of undiagnosed diabetes estimated from ELSA-Brasil is similar for both sexes (50.2\% in women and $51.5 \%$ in men; $P=0.53$ ). The highest proportion of undiagnosed cases occurs in women aged 70-79 (61.9\%) and men aged 60-69 (61.5\%) (Table 1).

The adjusted mortality rate ratio for self-reported diabetes among ELSA-Brasil participants decreased with age, from $2.38(95 \%$ confidence interval $(\mathrm{CI})=1.14-5.01)$ at age 35 to $1.42(95 \% \mathrm{CI}=0.877-2.29)$ at age 70 in women, and from $2.76(95 \% \mathrm{CI}=1.33-5.70)$ at age 35 to $1.88(95 \% \mathrm{CI}=1.32-2.68)$ at age 70 in men (Figure 2, panel A). At age 80, the estimated adjusted diabetes mortality rate ratios were 1.22

Table 1. Proportion (\%) of undiagnosed diabetes cases by sex and age group in ELSA-Brasil, 2008-2010

\begin{tabular}{cccc} 
Age group & Women (\%) & Men (\%) & P-IALUE \\
$35-49$ & 40.9 & 43.0 & 0.63 \\
\hline $50-59$ & 49.5 & 50.6 & 0.76 \\
\hline $60-69$ & 56.9 & 61.4 & 0.25 \\
\hline $70-79$ & 61.9 & 53.2 & 0.33 \\
\hline Total & 50.2 & 51.5 & 0.53 \\
\hline
\end{tabular}

*P-values are calculated from Fisher Exact Test for the difference between men and women. 


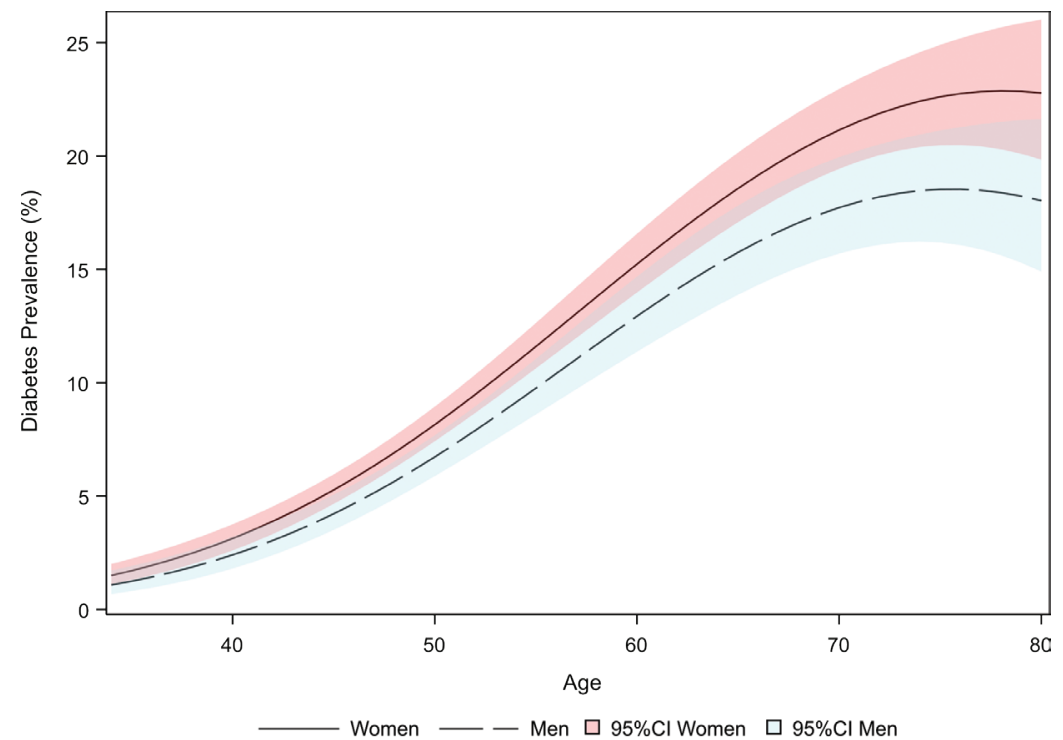

Figure 1. Prevalence of diagnosed diabetes (\%) for Brazilian men (dashed line; blue) and women (solid line; red). National Health Survey (Pesquisa Nacional de Saúde, PNS), Brazil, 2013.

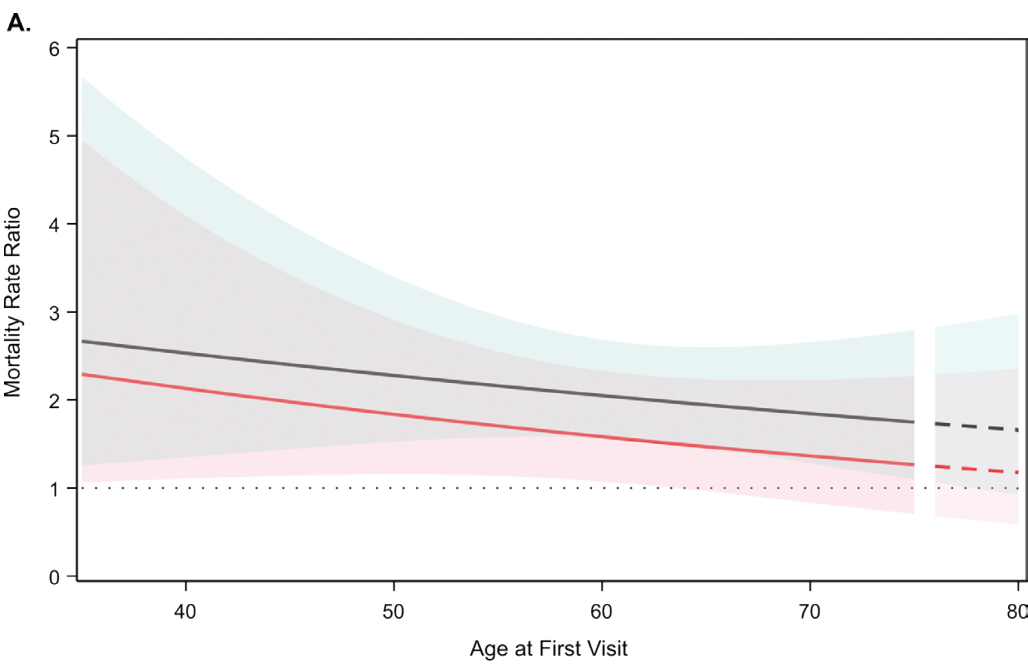

B.

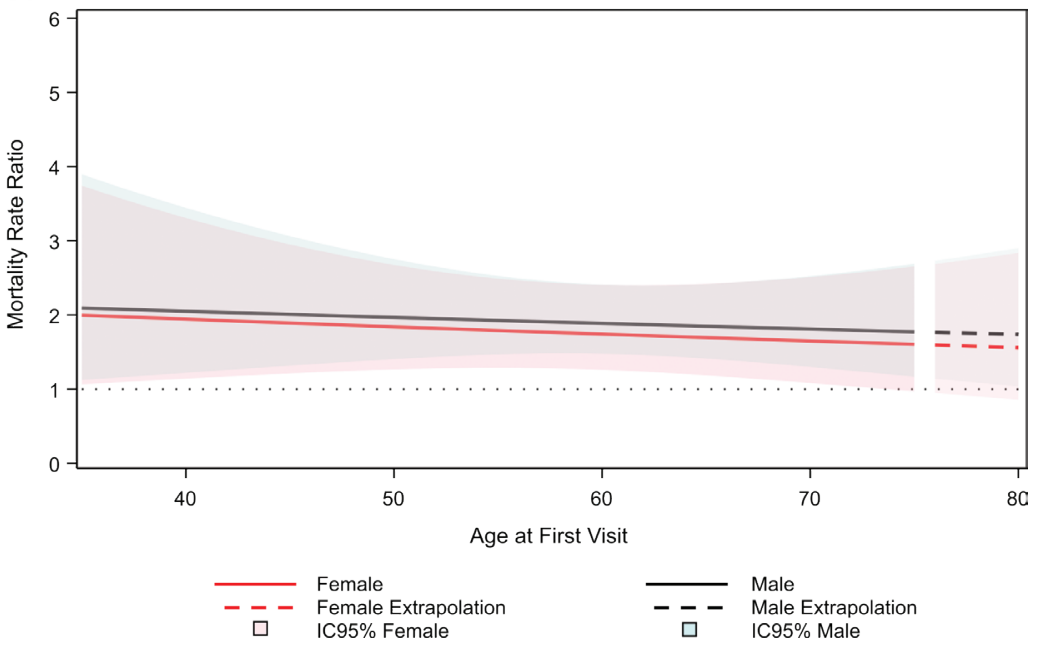

Figure 2. Adjusted mortality rate ratio (diabetes vs non-diabetes) (adjusted for ethnicity, educational level, income, smoking status, BMI and waist circumference). Panel A. Self-reported. Panel B. Self-reported plus undiagnosed diabetes. Men - black line, for men, blue confidence zone, women - red line, pink confidence zone. Estimates between ages 75 and 80 years old (small dashed lines) are extrapolations. ELSA-Brasil, 2008-2018. 
(95\% CI =0.618-2.41) and $1.69(95 \% \mathrm{CI}=0.96-2.98)$ respectively. Values are extrapolated after age 75 and presented with a dashed line. The mortality rates for people with and without diabetes, obtained by combining overall mortality rates with the diabetes mortality rate ratio, were consistently higher in men than in women in all ages. Interestingly, in men without diabetes the mortality rate reached that of women with diabetes (Figure 3, panel A).

When undiagnosed diabetes cases were considered, the mortality rate ratios decreased slightly, changed less across the age range, and were similar for men and women (Figure 2, panel B).

Combining the above rates of self-reported diabetes with mortality rate ratios and national population estimates, we calculated 65581 deaths in 2013 as being attributable to diagnosed diabetes (Table 2) 9.1\% of all deaths for that year. Excess deaths, in absolute numbers and as a fraction of the total deaths, were higher in men (44591, PAF 10.5\%) than in women (20990, PAF 7.2\%). In age-stratified analyses, the PAF was $4.9 \%$ among those aged $35-49$, and peaked at $11.3 \%$ in those aged $60-69$. When accounting for undiagnosed diabetes, the large increase in prevalence and the smaller decrease with age in the mortality rate ratio resulted in an increase in the excess deaths due to diabetes, with an estimate of 102350 deaths attributable to diagnosed diabetes and a corresponding PAF of 14.3\%. In this scenario, although the absolute number of excess deaths is still higher in men (58228) than in women (44 122), the proportion of total deaths attributable to diabetes is slightly higher in women (15.1\%) than in men (13.7\%).

The diabetes mortality burden estimated from death certificate data in Brazil's national mortality system was $5.3 \%$ when diabetes was the underlying cause and $10.4 \%$ when any mention of diabetes appeared on any line of the death certificate. Both estimates were higher in women than in men (Table 2).

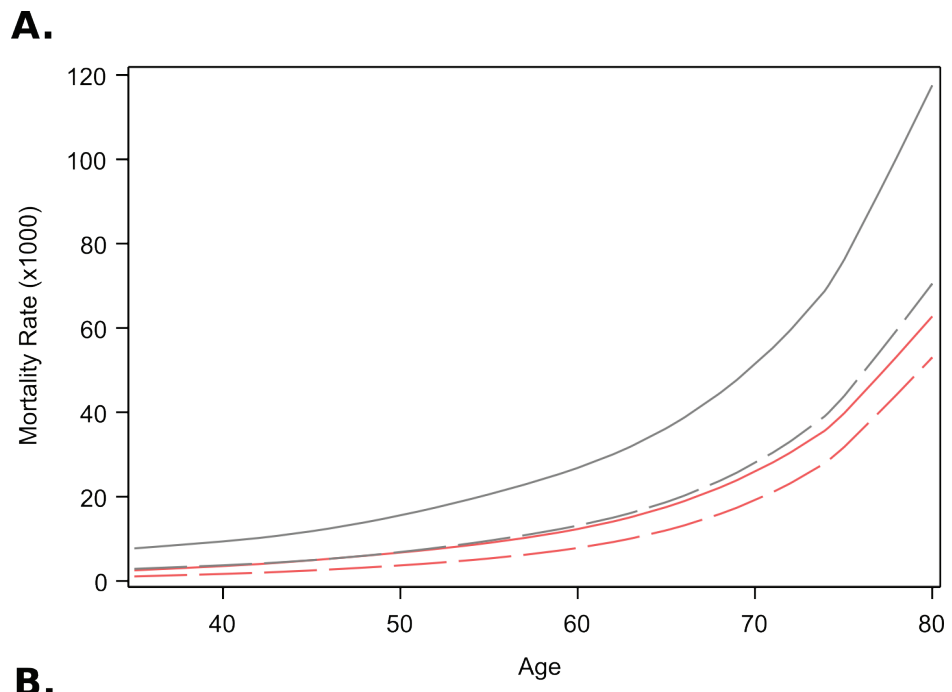

B.

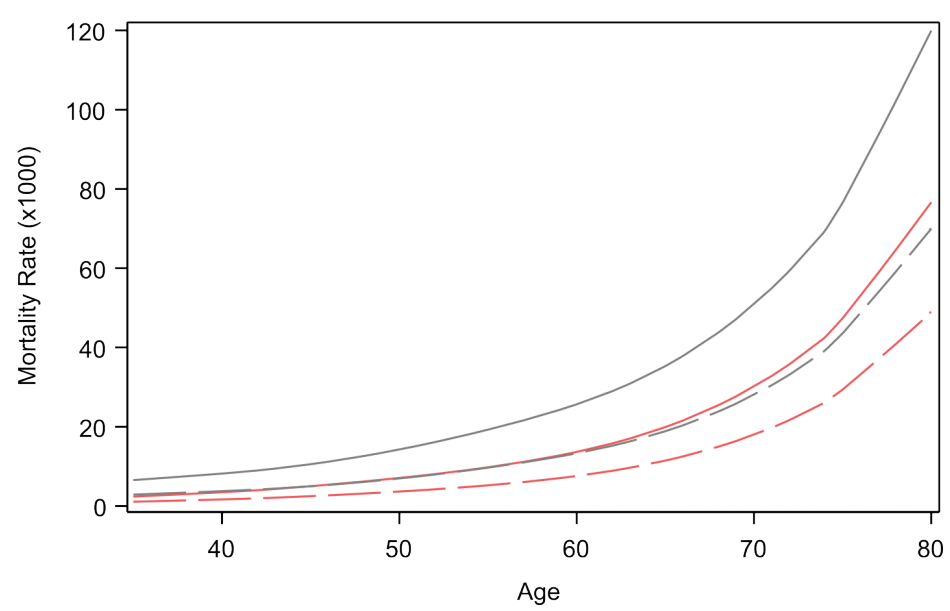

Figure 3. Mortality rates. Panel A. Self-reported. Panel B. Self-reported plus undiagnosed diabetes. Men - black lines, women - red lines. Dashed lines represent mortality of those without diabetes. Brazil, 2013. 


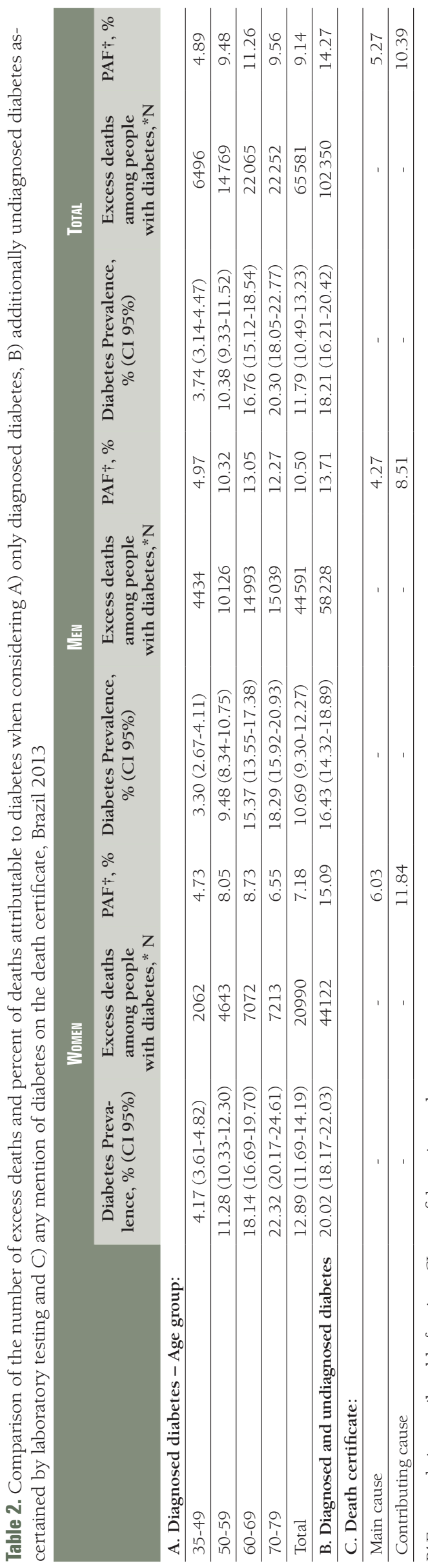

\section{DISCUSSION}

This is the first nationwide estimate of excess deaths attributable to diabetes in Brazil, and one of the few estimates of this burden in low- and middle-income countries. Compared to those without diabetes, mortality of those with known diabetes was 2.76 and 1.88 times higher among middle-aged and elderly men; and 2.38 and 1.42 times higher among middle-aged and elderly women, respectively. In 2013, 65581 deaths, approximately $9 \%$ of all deaths between the ages of $35-80$, could have been prevented if the mortality rate were the same between those with and without known diabetes. Given the large fraction of total diabetes cases ascertained only by laboratory measurements in ELSA, if excess deaths among these cases of unknown diabetes were also considered, this figure would rise to $14 \%$.

In contrast, the Global Burden of Disease Study estimated that, in 2013, only 5.1\% of all deaths in Brazil were due to diabetes among individuals between 50 and 69 years old, and only $4.2 \%$ when considering all ages [15]. These estimates are largely based on data of the Brazilian Mortality Registry (Sistema de Informações sobre Mortalidade, or SIM), in which $5.3 \%$ of death certificates indicated diabetes as the underlying cause. Using death certificates as the principal source of mortality data to guide Brazilian public health decisions thus estimates a diabetes mortality burden approximately $50 \%$ less than that which we report. The Brazilian vital registration system has improved considerably in recent decades [16]. However, estimating diabetes mortality burden from death certificate data are challenging and considerably less sensitive in detecting deaths attributable to diabetes than data sources such as administrative records or surveys [5]. This difference largely results from the fact that most individuals with diabetes have multiple comorbidities and complications that contribute to their cause of death [17]. As only one main cause is permitted when following the International Classification of Diseases, other conditions, especially cardiovascular and renal diseases, are often chosen, leaving an unrecognized contribution of diabetes. Given the complications in estimation due to the multicausality of diseases and deaths, our cohort-based analysis, which permits a direct contrast in risk of death between those with and without diabetes, provides a more appropriate estimate.

Of note, if we consider as diabetes-related deaths those with mention of diabetes on any line of the death certificate [18], the percentage of 2013 diabetes-related deaths between 35 and 80 years rises to $10.4 \%$, close to the attributable fractions estimated based on our cohort data. This similarity demonstrates that, in the absence of cohort data, the fraction of deaths having diabetes listed anywhere on the death certificate appears to be a more reasonable estimate of the true diabetes mortality burden.

For 2013, the International Diabetes Federation, applying a similar analysis, estimated that 226371 deaths (11.6\% of total deaths) were attributable to diabetes in adults of Central and South America aged between 20-79 years [19]. These estimates, although close to our results, are an approximation 
for the whole region and are based on sex- and age-specific relative risks of death between individuals with and without diabetes derived from United States (US) National Health and Nutrition Examination Surveys (NHANES) performed between 1971 and 1993 [20]. As NHANES is representative of the United States population, our use of relative diabetes mortality obtained from a Brazilian cohort allows a more valid estimate for the Brazilian diabetes mortality burden.

The majority of studies reporting excess deaths based on relative risk or the rate ratio of mortality for diabetes comes from high-income countries. A meta-analysis of 97 prospective cohorts in 25 countries (all but two of them high-income) showed that persons with diabetes had almost twice the rate of death from any cause as those without the disease [21]. In the United States, for the period of 1999-2010, the estimated hazard ratio for those with vs without diabetes, aged 34 to 80 years old, was 2.0 ( $95 \%$ CI = 1.752.28) for self-reported diabetes and 1.88 (95\% CI=1.63-2.16) for diabetes diagnosed by HbAlc criteria or self-reported use of an oral hypoglycemic agent or insulin [22]. As in our findings, the diabetes mortality hazard ratio (HR) observed for the United States also decreased with age. A similar pattern was described for the Swedish population included in their National Diabetes Register on or after 1998 and followed until 2011, with a diabetes mortality HR of 2.59 (95\% CI=2.27-2.96) for individuals younger than 55 years old and $1.03(95 \% \mathrm{CI}=1.01-1.06)$ for those older than 75 years of age [23].

Attributable fractions similar to ours have been reported previously. A recent study from Germany, using insurance claims data to estimate diagnosed type 2 diabetes of individuals between 40 and 99 years, concluded that approximately $16.4 \%$ of deaths occurring in 2010 could have been avoided if the mortality rate of those with diabetes equaled that of those without the disease [14]. From the NHANES data, the diabetes mortality PAF was $11.8 \%$ for self-reported diabetes in the US population aged 30 to 84 years and $11.7 \%$ when using HbAlc criteria [22].

Application of data from longitudinal studies in the calculation of national diabetes-related outcomes data are rare for low and middle-income countries. The only study we located, which shows recent results from Mexico, found considerably greater risks of death associated with diabetes than observed in high income countries, with the diabetes death rate ratio ranging from 5.4 (95\% CI=5.0-6.0) for individuals aged 35 to 59 years to $1.9(95 \% \mathrm{CI}=1.8-2.1)$ for those 75 to 84 years old. Considering excess deaths, $30 \%$ of all deaths of Mexicans between ages 35 to 74 years were due to diabetes; this estimate increased to $35 \%$ when including undiagnosed diabetes [24]. A more favorable ratio in Brazil than in Mexico could be the result of decreases in diabetes mortality rates, as has been observed in death certificate data in Brazil over the last decade [25]. Additionally, we observed trends to lower mortality due to acute complications of diabetes from 1991 to 2010 [26]. These declines occurred in parallel to improvements of the Brazilian National Health System (SUS) coverage, especially relating to primary care, which provided greater access to medications such as antibiotics and insulin and to qualified care. Similar findings have been reported for many high-income countries [27-29].

The Mexican and Swedish studies reported virtually identical relative diabetes mortality rates for men and women and no significant interaction between sex and diabetes for all-cause mortality, respectively $[23,24]$. Although we also found no significant difference, we consistently found higher diabetes mortality rate ratios in men than in women for all ages, the difference being considerably wider when not including undiagnosed diabetes. A possible explanation for these findings is that milder cases are more likely to go undiagnosed in Brazilian men than in Brazilian women with diabetes.

Even though diabetes prevalence was higher in women, the percentage of total deaths due to diabetes was higher in men for self-reported diabetes, in contrast with the findings for the US population [22]. However, the decrease in the mortality rate ratio difference between sexes and across ages after accounting for undiagnosed diabetes resulted in a slightly higher PAF for women. This second finding is in accordance to what has been reported when analyzing death certificates, ie, that the diabetes mortality rate in Brazil in recent years has been higher in women than in men [25]. The higher rates for women can in part be due to the greater diagnosis of the disease in women, as they tend to seek more health services, thereby obtaining the diagnosis of diabetes more often than men [30]. The higher prevalence of diabetes in women results in their deaths representing a higher fraction of the total deaths, however it may suggest that our results could be underestimating the diabetes mortality burden in men.

Limitations to our study merit consideration. The ELSA cohort is not a representative sample of the entire Brazilian population, since it consists of university and research institute employees with stable jobs who, in comparison with the general population, have greater educational attainment, a greater proportion of white ethnicity, and higher income. However, in terms of self-reported diabetes, its results are similar to those found in representative surveys of the Brazilian state capitals [12]. Moreover, our estimates of dia- 
betes mortality rate ratio are adjusted not only for age, sex, BMI, and central obesity, but also for ethnicity, smoking status, educational level, and income. Another possible limitation is that our estimation of unknown diabetes is based on one of several glycemic tests, some of which present large within-individual variability. Studies suggest that approximately $25 \%$ of those ascertained as having diabetes based on one laboratory determination will not be positive on retesting [31]. Thus, while these estimates may be accurate for "known diabetes plus those who would be ascertained on single testing as having diabetes", they overestimate the PAF for known and unknown diabetes. However, even if only half of those ascertained with undiagnosed diabetes on single testing in ELSA in fact had unknown diabetes, the increase in estimated excess deaths and PAF would remain notable.

Within these limitations, ELSA provides accurate and necessary data to estimate the diabetes mortality burden. When coupled with nationally representative estimates of prevalence of diabetes and overall estimates of mortality rates, these data obviate the need to use death certificate cause of death information. In addition, it also allows us to differentiate the mortality rate ratio for self-reported diabetes alone and when accounting for undiagnosed diabetes. Therefore, even with our limitations, these results contribute greatly to the scarce information published about diabetes burden in low- and middle-income countries.

\section{CONCLUSION}

In conclusion, combining longitudinal cohort data of ELSA-Brasil with national diabetes prevalence data from the PNS and national mortality data, we calculated the absolute number of excess deaths for individuals with diabetes in Brazil in 2013. We believe that this is the first report of the diabetes mortality burden in Brazil based on means other than death certificates, which underestimate the importance of diabetes as a cause of death. We found that, despite a recent lowering in diabetes mortality rates, the diabetes mortality burden is quite high in Brazil $-9.1 \%$ when considering only self-reported diabetes, and $14.3 \%$ when adding undiagnosed diabetes ascertained with a single determination. These data emphasize the importance of greater actions by Brazilian society and governments to confront the ongoing obesity and diabetes epidemics.

\footnotetext{
Acknowledgements: The authors thank the staff and participants of ELSA-Brasil, PNS and Vigitel for their important contributions.

Disclaimer: The findings and conclusions in this report are those of the authors and do not necessarily represent the official position of the Centers for Disease Control and Prevention.

Ethics: Elsa-Brasil, PNS and Vigitel were approved by the National Commission for Ethics in Research (CONEP). All study subjects gave written or verbal consent prior to their participation.

Availability of data and materials: The ELSA-Brasil dataset is available from the corresponding author on a reasonable request. The datasets used from PNS, VIGITEL and SIM are public available respectively in the following links: PNS: https://ww2.ibge.gov.br/home/estatistica/populacao/pns/2013/default_microdados. shtm. VIGITEL: http://svs.aids.gov.br/bases_vigitel_viva/vigitel.php. SIM: http://www2.datasus.gov.br/DATASUS/index.php?area=0901 \&item $=1$ \&acao=26\&pad=31655http://www2 .datasus.gov.br/DATASUS/index . php?area $=0901$ \&item $=1$ \&acao $=26 \&$ pad $=31655$.

Authorship contribution: PAB gathered the data and did the data analysis. BBD, MIS, EWG and DBR mentored the work and the analysis. All authors made meaningful revisions to the manuscript.

Funding: The study is supported by the Brazilian Ministry of Health (Department of Science and Technology) and Ministry of Science, Technology and Innovation (FINEP, Financiadora de Estudos e Projetos), grants No. 0106 0010.00, 0106 0212.00, 0106 0300.00, 0106 0278.00, 01060115.00 and 01060071.00 and CNPq (the National Council for Scientific and Technological Development). PAB received a fellowship from CAPES (Coordenação de Aperfeiçoamento de Pessoal de Nível Superior). Researchers were independent from funders. Funders had no role in the study design; the collection, analysis, and interpretation of data; the writing of the report; or the decision to submit the article for publication. The corresponding author affirms that she had full access to all the data in the study and had final responsibility for the decision to submit for publication.

Competing interests: The authors completed the ICMJE Unified Competing Interest form (available upon request from the corresponding author), and declare no conflicts of interest.
} 
1 International Diabetes Federation. IDF Diabetes Atlas 2017. Brussels: International Diabetes Federation; 2017.

2 Ministério da Saúde. Secretaria de Vigilância em Saúde. VIGITEL Brasil 2016: Vigilância de fatores de risco e proteção para doenças crônicas por inquérito telefônico [Surveillance of Risk and Protective Factors for Chronic Diseases, Vigitel,2016]. Brasília: Ministério da Saúde; 2017.

3 Duncan BB, Schmidt MI, Ewerton Cousin, Moradi-Lakeh M, Passos VM de A, França EB, et al. The burden of diabetes and hyperglycemia in Brazil-past and present: findings from the Global Burden of Disease Study 2015. Diabetol Metab Syndr. 2017;9:18. Medline:28293304 doi:10.1186/s13098-017-0216-2

4 International Diabetes Federation. IDF Diabetes Atlas 2015. Brussels: International Diabetes Federation; 2015.

5 Saydah SH, Geiss LS, Tierney E, Benjamin SM, Engelgau M, Brancati F. Review of the performance of methods to identify diabetes cases among vital statistics, administrative, and survey data. Ann Epidemiol. 2004;14:507-16. Medline:15301787 doi:10.1016/j.annepidem.2003.09.016

6 Alegre-Díaz J, Herrington W, López-Cervantes M, Gnatiuc L, Ramirez R, Hill M, et al. Diabetes and cause-specific mortality in Mexico City. N Engl J Med. 2016;375:1961-71. Medline:27959614 doi:10.1056/NEJMoal605368

7 Boyko EJ. Progress in the Estimation of Mortality due to Diabetes. Diabetes Care. 2005;28:2320-1. Medline:16123511 doi:10.2337/diacare.28.9.2320

8 Damacena GN, Szwarcwald CL, Malta DC, de Souza Júnior PRB, Vieira MLFP, Pereira CA, et al. The Development of the National Health Survey in Brazil, 2013. Epidemiol Serv Saude. 2015;24:197-206. doi:10.5123/S1679-49742015000200002

9 Iser BPM, Stopa SR, Chueiri PS, Szwarcwald CL, Malta DC, Monteiro HO da C, et al. Self-reported diabetes prevalence in Brazil: results from National Health Survey 2013. Epidemiol Serv Saude. 2015;24:305-14. doi:10.5123/S167949742015000200013

10 IBGE. Instituto Brasileiro de Geografia e Estatística. Available: https://ww2.ibge.gov.br/home/estatistica/populacao/projecao_da_populacao/2013/default.shtm. Accessed: 15 September 2018.

11 Aquino EML, Barreto SM, Bensenor IM, Carvalho MS, Chor D, Duncan BB, et al. Brazilian Longitudinal Study of Adult Health (ELSA-Brasil): Objectives and design. Am J Epidemiol. 2012;175:315-24. Medline:22234482 doi:10.1093/aje/ kwr294

12 Schmidt MI, Duncan BB, Mill JG, Lotufo PA, Chor D, Barreto SM, et al. Cohort profile: Longitudinal Study of Adult Health (ELSA-Brasil). Int J Epidemiol. 2015;44:68-75. Medline:24585730 doi:10.1093/ije/dyu027

13 Lenner P. The Excess mortality rate: A useful concept in cancer epidemiology. Acta Oncol. 1990;29:573-6. Medline:2206568 doi:10.3109/02841869009090053

14 Jacobs E, Hoyer A, Brinks R, Kuss O, Rathmann W. Burden of mortality attributable to diagnosed diabetes: A Nationwide analysis based on claims data from 65 million people in Germany. Diabetes Care. 2017;40:1703-9. Medline:28993421 doi:10.2337/dc17-0954

15 Institute for Health Metrics and Evaluation (IHME). GBD Compare. Available: http://vizhub.healthdata.org/gbd-compare. Accessed: 15 September 2018.

16 Lima EE, Queiroz BL. Evolution of the deaths registry system in Brazil: associations with changes in the mortality profile, under-registration of death counts, and ill-defined causes of death. Cad Saude Publica. 2014;30:1721-30. Medline:25210911 doi:10.1590/0102-311X00131113

17 Morrish NJ, Wang S-L, Stevens LK, Fuller JH, Keen H. Mortality and causes of death in the WHO multinational study of vascular disease in diabetes. Diabetologia. 2001;44 Suppl 2:S14-21. Medline:11587045 doi:10.1007/PL00002934

18 DATASUS. Available: http://www2.datasus.gov.br/DATASUS/index.php?area=060701. Accessed: 15 September 2018.

19 IDF Diabetes Atlas Group. Update of mortality attributable to diabetes for the IDF Diabetes Atlas: Estimates for the year 2013. Diabetes Res Clin Pract. 2015;109:461-5. Medline:26119773 doi:10.1016/j.diabres.2015.05.037

$20 \mathrm{Gu}$ K, Cowie CC, Harris MI. Mortality in Adults With and Without Diabetes in a National Cohort of the U.S. Population, 1971-1993. Diabetes Care. 1998;21:1138-45. Medline:9653609 doi:10.2337/diacare.21.7.1138

21 Rao Kondapally Seshasai S, Kaptoge S, Thompson A, Di Angelantonio E, Gao P, Sarwar N, et al. Diabetes mellitus, fasting glucose, and risk of cause-specific death. N Engl J Med. 2011;364:829-41. Medline:21366474 doi:10.1056/NEJMoal008862

22 Stokes A, Preston SH. Deaths attributable to diabetes in the United States: Comparison of data sources and estimation approaches. Schooling CM, organizador. PLoS One. 2017;12:e0170219. Medline:28121997 doi:10.1371/journal. pone.0170219

23 Tancredi M, Rosengren A, Svensson A-M, Kosiborod M, Pivodic A, Gudbjörnsdottir S, et al. Excess mortality among persons with Type 2 Diabetes. N Engl J Med. 2015;373:1720-32. Medline:26510021 doi:10.1056/NEJMoa1504347

24 Alegre-Díaz J, Herrington W, López-Cervantes M, Gnatiuc L, Ramirez R, Hill M, et al. Diabetes and cause-specific mortality in Mexico City. N Engl J Med. 2016;375:1961-71. Medline:27959614 doi:10.1056/NEJMoal605368

25 Schmidt MI, Duncan BB, Ishitani L, da Conceição Franco G, de Abreu DMX, Lana GC, et al. Trends in mortality due to diabetes in Brazil, 1996-2011. Diabetol Metab Syndr. 2015;7:109. Medline:26617678 doi:10.1186/s13098-015-0105-5

26 Klafke A, Duncan BB, Stevens A, Rosa R dos S, de Moura L, Malta D, et al. The decline in mortality due to acute complications of diabetes mellitus in Brazil, 1991-2010. BMC Public Health. 2015;15:772. Medline:26259708 doi:10.1186/ s12889-015-2123-5

27 Gregg EW, Cheng YJ, Srinivasan M, Lin J, Geiss LS, Albright AL, et al. Trends in cause-specific mortality among adults with and without diagnosed diabetes in the USA: an epidemiological analysis of linked national survey and vital statistics data. Lancet. 2018;391:2430-40. Medline:29784146 doi:10.1016/S0140-6736(18)30314-3 
28 Harding JL, Shaw JE, Peeters A, Guiver T, Davidson S, Magliano DJ. Mortality trends among people with type 1 and type 2 diabetes in Australia: 1997-2010. Diabetes Care. 2014;37:2579-86. Medline:24947787 doi:10.2337/dc14-0096

29 Lind M, Garcia-Rodriguez LA, Booth GL, Cea-Soriano L, Shah BR, Ekeroth G, et al. Mortality trends in patients with and without diabetes in Ontario, Canada and the UK from 1996 to 2009: a population-based study. Diabetologia. 2013;56:2601-8. Medline:24114114 doi:10.1007/s00125-013-3063-1

30 Schmidt MI, Hoffmann JF, de Fátima Sander Diniz M, Lotufo PA, Griep R, Bensenor IM, et al. High prevalence of diabetes and intermediate hyperglycemia - The Brazilian Longitudinal Study of Adult Health (ELSA-Brasil). Diabetol Metab Syndr. 2014;6:123. Medline:25788987 doi:10.1186/1758-5996-6-123

31 Selvin E. Short-term Variability in measures of glycemia and implications for the classification of diabetes. Arch Intern Med. 2007;167:1545. Medline:17646610 doi:10.1001/archinte.167.14.1545 